\title{
REFLEXIONES SOBRE LA CERÁMICA TIPO CARAMBOLO: ¿UN AXIOMA DE LA ARQUEOLOGÍA PROTOHISTÓRICA DEL SUROESTE ANDALUZ?
}

\section{SOME REFLECTIONS CONCERNING THE “CARAMBOLO” TYPE POTTERY: AN AXIOM OF THE PROTOHISTORIC ARCHAEOLOGY OF THE ANDALUSIAN SOUTH-WEST?}

\author{
por \\ MANUEl JosÉ CASADO ARIZA
}

RESUMEN En primer, lugar planteamos una reflexión sobre este peculiar tipo cerámico, pero no acerca de cuestiones meramente formales, sino en torno a una serie de matices coyunturales que rodearon el momento de la aparición de la cerámica tipo Carambolo en el panorama científico y que, a nuestro entender, influyeron en la posterior interpretación que de ella se hizo.

Por otro lado, a la luz de los nuevos descubrimientos y de las nuevas hipótesis de trabajo sugeridas en los últimos años, y dejando a un lado cierta herencia historiográfica, quizá sea posible abrir otras líneas de interpretación que ayuden a aclarar la incertidumbre que rodea a esta vajilla, así como otros aspectos oscuros del trạ́nsito del Bronce Final al Hierro I.

ABSTRACT Firstly, we propose a reflexion about this particular type of pottery, but not only about it's formal aspects, but also about the particular social and scientific conditions that sorrounded the introduction of the Carambolo Type of pottery in scientific sector which affected, or so we believe, in the follewing interpretation of this discovery.

On the other side, thanks to the recent descoveries and the innovative working hipothesis sugested in recent years, it's possible to open new interpretation lines that help to bring some light the cofussion surronding this kind of pottery, and clarify some obscure aspects of the transition from the Final Bronze period to the First Iron Age.

Palabras claves

Cerámica tipo Carambolo, Tartessos, fenicios, Bronce Final/Hierro I, Astarté, cáscara de huevo de avestruz, decoración geométrica.

Key words

Carambolo type of pottenf, Tartessos, phoenicians, Final Bronze/First Iron, Astarte, ostrich's egg shell, geometric decoration. 
Teniendo en cuenta la importante labor precedente realizada por otros investigadores, en este trabajo pretendemos hacer un análisis y una reflexión sobre este tipo cerámico, que con su aparición dio un cuerpo material a la cultura tartésica. Tratamos aquí aspectos que incidieron, directa o indirectamente, sobre la opinión científica del momento, y que condujeron en aquel instante a la formación de una sólida concepción del significado de esta especie cerámica, reconociéndose su adscripción inequívoca al mundo tartésico. Por todo esto, en este estudio obviaremos ciertos aspectos ya suficientemente tratados en otros trabajos, centrando pues nuestro interés en aquellas características de la cerámica tipo Carambolo ${ }^{1}$ que mayores problemas suelen plantear y donde la comunidad científica encuentra más desacuerdos: cronología, uso y sus posibles influencias exteriores. Por otro lado, este análisis pretende arrojar una visión renovada al calor de los nuevos descubrimientos y planteamientos teóricos que existen actualmente en torno al tránsito del Bronce Final a la Primera Edad del Hierro en el suroeste ibérico.

\section{BUSCANDO A ARGANTONIO}

Tarschisch (Tartessos), en cambio, la primera ciudad comercial y el más antiguo centro cultural de Occidente, después de haber sido destruida por la envidia de los Cartagineses, quedó envuelta en las sombras de una tradición desfavorable y cayó en el más profundo olvido.

(Schulten 1945: 9)

Para seguir el rastro a la CTC, y analizar cómo llegó a convertirse en fósil guía de la cultura tartésica, quizá haya que volver la vista al principio mismo de las investigaciones arqueológicas sobre Tartessos. Así pues, debemos remontarnos hasta la figura de Adolf Schulten, que, como sabemos, tuvo gran influencia para asentar el concepto literario de Tartessos en la mente de los investigadores de su época e incluso posteriores. Las fuentes, al ofrecer una imagen de cultura llena de esplendor y riqueza, de un reino en el que sus longevos reyes colmaban de atenciones a los visitantes, son, por lo tanto, las responsables de que el mito del dorado Tartessos se dibujase con fuerza en las mentes de los académicos, que impulsados por un espíritu romántico soñaban con desenterrar sus áureas murallas. Tal fue el caso de Schulten, que a lo largo de más de treinta años, armado con las fuentes clásicas en la mano y en el ánimo el férreo convencimiento de que iba por buen camino, recorrió el Coto de Doñana, entre otras zonas del sur de la Península Ibérica, rastreando cada centímetro cuadrado en busca de la legendaria ciudad. Schulten no cesó en su empeño y emulando a Schliemann siguió a pies juntillas los datos geográficos de las fuentes, para situar la mítica ciudad, centro del imperio tartésico. Incluso elaboró un mapa donde se aprecian, sobre puntos geográficos actuales, una serie de lugares mencionados en las fuentes (Schulten 1945: mapa II). Como sabemos, a pesar del afán puesto por Schulten, su búsqueda fue del todo infructuosa. Los fracasos se sucedieron uno tras otro durante todos aquellos años, creando un ambiente de escepticismo en los círculos científicos, dado que no se encontraban por ningún lado pruebas de la existencia de la ciudad legendaria ni de su cultura (Aubet 1992: 36). Durante la década de los cuarenta del siglo XX, otros investigadores, como Martín de la Torre, Chocomeli, Antón y Pemán entre otros, siguieron la línea de Schulten, el cual había adquirido un gran peso en el pensamiento de los investigadores españoles de la primera mitad de dicho siglo (Aubet 1992: 37), transmitiéndoles a éstos con su obra la imagen del dorado esplendor de Tartessos retratada en la literatura clásica. Con las fuentes como guía, éstos también intentaron, a su vez, situar la legendaria ciudad,

1. En adelante CTC. 
pero igualmente sin éxito. Ante este desolador panorama, se llegó, a principios de los cincuenta del siglo XX, a una situación de impotencia total para caracterizar la cultura tartésica. Únicamente lo escrito en las fuentes ofrecía alguna información sobre esta legendaria cultura. Desde el punto de vista estrictamente arqueológico había una ausencia total de hallazgos debidamente contextualizados.

Esta situación llevó a algunos autores, de principios de la segunda mitad del siglo $\mathrm{XX}$, a realizar una revisión de algunos materiales hallados en la zona de la baja Andalucía (cf. Aubet 1992: 38), buscando desesperadamente dar un cuerpo material a los fantasmas tartésicos de las fuentes. Este conjunto de materiales se reduce a jarros de bronce, marfiles, joyas y demás elementos de cierta entidad, cercanos a esa imagen de mítica riqueza, para los cuales se empezó a acuñar el término "orientalizante".

\title{
DESENTERRANDO LA CULTURA TARTÉSSICA
}

\begin{abstract}
Desde que el tesoro ha aparecido, se impone un nombre: civilización tartesa. [...] Es un arte nuestro. Por un lado imitación fenicia, con modelo egipcio y la perfección de lo griego. Es muy andaluz [...] Y la afirmación rotunda, ya constatada, de que no se trataba de un mito [...]

Juan de Mata Carriazo, ABC 10 de octubre de 1958.
\end{abstract}

El tesoro del Carambolo vio la luz el 30 de Septiembre de 1958. Fue encontrado, en la localidad sevillana de Camas, durante el transcurso de unas obras de adecuación en las instalaciones de la Sociedad de Tiro Pichón, propietaria del terreno, para los campeonatos de 1960.

D. Juan de Mata Carriazo, por aquel entonces delegado del Servicio Nacional de Excavaciones Arqueológicas, tras examinar el tesoro, emprendió la excavación del lugar donde se había producido tan magnífico hallazgo. Carriazo también contó con la visita y ayuda de D. Juan Maluquer de Motes. Durante el tiempo que duraron las excavaciones, llevadas a cabo en dos sectores del cerro, Carambolo Alto y Carambolo Bajo, se realizaron numerosísimos hallazgos sobre los cuales Carriazo nos informa en su voluminosa obra Tartesos y el Carambolo (Carriazo 1973). Dichos hallazgos (las edificaciones, el fondo de cabaña, los bronces, el tesoro y, ante todo, la novedosa cerámica con decoración geométrica que ahora nos ocupa) fueron adscritos sin dudarlo ni un segundo a la supuestamente gloriosa civilización tartésica, aunque el resultado de la excavación, en lo que a estructuras arquitectónicas se refiere, no cubrió las expectativas de Carriazo, que las juzgó demasiado pobres para la idea de riqueza que transmitían las joyas, que ya la opinión pública había atribuido al mismísimo Argantonio.

El abundante registro cerámico recogido en el cerro del Carambolo supuso todo un descubrimiento, ya que, aparte de cerámica de procedencia fenicia, se constataron otros tipos variados, hasta aquel momento, desconocidos. Entre todos los que Carriazo recoge en su obra, el que resultó más destacado por su originalidad y desconocimiento hasta la fecha, fue el que el autor propuso como tipo 18 y que automáticamente bautizó como cerámica tartésica (Carriazo 1973: 484 y 504). Esta clase fue hallada en un número ingente de fragmentos en el fondo de cabaña y, así como la 17 (de retícula bruñida), apareció en los estratos inferiores del yacimiento (Carriazo 1973: 485). Lo que más sorprendió a Carriazo fue la gran variedad de tipos cerámicos y el elevado número de fragmentos que se localizaron en un espacio tan reducido, a lo cual dio la explicación de que, o bien la cabaña fue ocupada durante mucho tiempo, o bien que los habitantes del Carambolo se servían de muchos recipientes, dando esta segunda como la más verosímil de las dos (Carriazo 1973: 487).

La aparición de este conjunto de hallazgos parecía la respuesta a las plegarias de muchos investigadores que habían removido con sus palas la tierra de media Andalucía buscando vestigios materiales de la 
civilización tartésica. El tesoro y la cerámica daban por fin cuerpo al mito recogido en las fuentes bíblicas y greco-latinas $y$, por eso, como se puede ver en el extracto de un artículo periodístico de la época que reproducimos sobre el título de este apartado (ABC 10 de octubre de 1958), nadie podía dudar de la pertenencia de estos hallazgos a los tartesios. Incluso años más tarde el propio Carrizo se reafirma en esta idea, mencionando, además, la rapidez y firmeza con que esa hipótesis fue aceptada: "Hoy, al cabo de diez años, mantengo lo que afirme desde el primer momento, y entonces con alta dosis de intuición: que el tesoro era tartésico. Esta calificación fue pronta y universalmente aceptada [...]" (Carriazo 1969: 311).

Para entender el hecho de que rápidamente se atribuyese toda esta serie de descubrimientos a una cultura de origen autóctono, aparte del clima científico, hay que sumergirse también en el clima político de la época. Por motivos ya conocidos, los libros de historia del momento cantaban con entusiasmo las glorias de la Reconquista y de los reyes de nuestro medioevo, de los Reyes Católicos y demás episodios históricos que hinchaban el orgullo del pueblo español. La búsqueda de la identidad nacional a través de la historia empujaba en cierto modo a pensar que Tartessos, la cultura más gloriosa y culta de toda la época prerromana, sólo podía ser una española. Todo esto puede deducirse analizando el tono empleado en las noticias periodísticas, y en algunos libros de historia.

Parece que los descubrimientos del Carambolo supusieron el pistoletazo de salida para un conjunto de nuevos hallazgos que se produjeron en los años siguientes dentro del ámbito territorial tartésico: Carmona, Huelva... Incluso se volvió sobre los materiales de las excavaciones de Bonsor en los Alcores, que podían ponerse en relación con este mundo emergente (cf. Aubet 1992: 40), y que aportaron nuevos datos que, añadidos a los del Carambolo, parecían dar forma al fenómeno Tartessos.

\section{SOBRE LA CRONOLOGÍA Y FILIACIONES DE LA CERÁMICA TIPO CARAMBOLO}

Son estos aspectos en los que los estudiosos han vertido más esfuerzo a la hora de ofrecernos una visión de conjunto de la CTC. Por lo tanto, son también los que más disparidad de opiniones nos brindan. Quizá no sea tanto variedad de opiniones como matices dentro de una opinión más o menos común, que podría quedar resumida en la inspiración de la CTC en el mundo geométrico griego, aunque rechazando la posibilidad de una relación estilística directa con éste.

Analizando más pormenorizadamente las cronologías y filiaciones que se han propuesto a lo largo de los últimos cincuenta años de investigación, podemos ver los matices antes referidos. J. de Mata Carriazo cita como precedentes del geometrismo tartésico al campaniforme y al esquematismo de la pintura prehistórica andaluza, y sitúa su origen en la época del Geométrico. Para este autor Tartessos tiene su inicio en el segundo milenio, con un período de florecimiento entre los siglos IX y V a.C. (Carriazo 1969: 340). M. Pellicer, que ve este tipo cerámico como la versión local del Geométrico Final (Pellicer 1969: 295), posteriormente matizará esta visión haciendo arrancar esta decoración desde el Campaniforme, que tras permanecer latente resurgirá con fuerza renovada gracias a la influencia egea, con una cronología que arranca desde la primeras mitad del siglo VIII a. C. (Pellicer 1987-88: 472). Dentro de los ocho grupos que establece M. Almagro-Gorbea (1977: 108 ss.) para las cerámicas del Bronce Final, el tercero es el denominado "Tipo Carambolo", y lo sitúa entre los siglos IX y VIII a.C. (Almagro-Gorbea 1977: 459), considerándolo de producción local pero con un origen oriental (Almagro-Gorbea 1977: 122 ss.). P. Cabrera da a la CTC una cronología entre los siglos IX y VIII a.C. (Cabrera 1981: 321) y engloba el tipo de decoración dentro de un fenómeno geométrico que se da de forma generalizada en el Mediterráneo, aunque tiene en cuenta que no se trata de una imitación directa ni de una versión provinciana de la cerámica griega. Para ella estos motivos decorativos son resultado de innovaciones locales (Cabrera 1981: 327). M. E. Aubet duda sobre la posibilidad de considerar un origen oriental para la cerámica pintada geométrica tartésica (Aubet 1982:387). J. Maluquer, aunque no da una 
cronología clara, difiere del resto y señala que la CTC, de origen local, imita claramente a las cerámicas chipriotas (Maluquer 1984:145). M. S. Buero sitúa la génesis de la CTC en relación con el fenómeno geométrico traído por lo colonos orientales, por tanto lo enmarca entre finales del siglo VIII y principios del VII a. C. (Buero 1984:351). D. Ruiz Mata, por su parte, propone una cronología desde la primera mitad del siglo IX a mediados del VIII a.C. (Ruiz Mata 1984-85:237), aunque apunta que debió originarse en el siglo X (Ruiz Mata 1980:15), afiliándola con el Geométrico Medio. En opinión de J. Fernández Jurado (1989-90: 268), esta cerámica se encuadraría dentro de lo que él llama el Tartésico Antiguo, momento anterior a todo contacto fenicio y por lo tanto nunca posterior a los inicios del siglo VIII a.C. Para M. Bendala la vajilla que aquí estudiamos tiene un origen claramente local, con precedentes técnicos y formales en una etapa previa de Tartessos, aunque afirma que su configuración final se debe a un influjo externo procedente de algún lugar impreciso del Mediterráneo oriental. Este autor sitúa su cronología inicial a principios del siglo IX a. C. (Bendala 1991: 12 - 13.). F. Amores pone a la CTC en relación con el mundo del Geométrico griego y ofrece paralelismos con producciones de Eubea, Rodas y Thera, que servirían como base estilística para el desarrollo de este estilo local, que según él hay que empezar a rastrear en la segunda mitad del siglo VIII (Amores 1995:166-167 y figs. 3.1-3.3). Es importante también la aportación que hace Amores al afirmar que, al contrario de lo que propuso Carriazo y de lo que se pensaba hasta la fecha, sí se recogieron piezas de cerámica a torno en los niveles inferiores del fondo de cabaña del Carambolo (Amores 1995: 162). Concretamente se refiere a dos fragmentos correspondientes a copas griegas que él data a fines del siglo VIII y principios del VII a.C. aproximadamente (Amores 1995: 165). Estas piezas griegas han sido objeto recientemente de una revisión, lanzándose la cronología de fines del VII y VI a. C. para las mismas y por tanto el autor ve factible la datación del estrato IV del Carambolo dentro del siglo VI (Schattner 2000:70-71). Castro y otros autores (1996: 198) coinciden en que la CTC es una producción propia de las comunidades tartésicas prefenicias de un período cronológico entre los siglos X-IX y que puede ponerse más en sincronía cronológica con el Protogeométrico que con el Geométrico propiamente.

Las similitudes con algunos motivos decorativos geométricos griegos (Buero 1987:42-43) y la presencia en el territorio tartésico de algunos fragmentos de cerámica de este período, o la inclusión de la CTC dentro de una fiebre geométrica mediterránea, son las razones que empujan a los científicos a relacionar nuestra cerámica con este mundo. Esta postura se adoptó desde el comienzo de las investigaciones sobre el mundo tartésico, a fines de los 60 y principios de los 70 , y no ha sido revisada.

Sin embargo, los motivos decorativos de la CTC guardan una gran similitud con otro tipo de objetos que nada tiene que ver con las cerámicas geométricas griegas: las cáscaras de huevos de avestruz decoradas de origen oriental. Carriazo ya advirtió este parecido (Carriazo 1973:509), sobre todo con el tema de cuadrados enmarcados por líneas (fig.2b). Concretamente Carriazo lo compara con el huevo hallado en la necrópolis de Villaricos (Carriazo 1973:511), al que atribuye una cronología del siglo ViI a. C. Posteriormente, de entre todos los investigadores que han tratado esta cerámica sólo M. S. Buero (1987:43) ha vuelto a tener en cuenta estas similitudes entre los motivos decorativos, sobre todo, como apuntó Carriazo, en lo que se refiere a los grandes triángulos rematados con roleos. Este motivo en concreto aparece también con frecuencia en la cerámica grabada de época tartésica, hermana claramente de la CTC, así como prácticamente todo el repertorio decorativo. M. Pellicer (1962:60) hace referencia a unos huevos de avestruz encontrados en la necrópolis de Laurita (en las tumbas 10 y nicho A de la 19) y los considera los más antiguos de la Península, y alude a que la decoración de éstos había sido realizada, a su entender, en España, ya que guardaban un gran parecido con los motivos pintados de una urna tipo Cruz de Negro (el vaso 136) hallado por Bonsor (fig. 2a). Sobre los huevos de avestruz y sus motivos decorativos, así como sobre su significado religioso tendremos que volver más adelante dado el parecido de algunos de estos motivos con los de la CTC. 
De todas las cronologías que hemos citado anteriormente, las que sitúan el origen de la CTC en un momento anterior al siglo VIII a. C., o a la llegada de los fenicios a las costas andaluzas, nos parecen demasiado elevadas, ya que en la mayoría de los yacimientos considerados tartésicos no es posible encontrar un horizonte de Bronce Final "puro" libre de indicios de contacto material, técnico o ideológico con colonos orientales (Escacena 1995). Un ejemplo evidente de los problemas de contextualización de la CTC lo proporciona el Cabezo del Castillo de Lebrija. En este yacimiento, la CTC aparece en niveles coloniales (Caro y otros 1986: 173), dando crédito a la hipótesis que reclama una cronología baja para esta alfarería y, en cualquier caso, más evidencias estratigráficas para poder elevar su datación a tiempos precoloniales.

Por tanto, se puede decir que no hay datos seguros que sitúen a la CTC en un momento anterior al siglo VIII. Así pues, una cronología para nuestra cerámica a partir del momento de llegada de los colonos orientales quizá se ajuste más a lo recabado en excavaciones.

A este respecto, las excavaciones realizadas recientemente en el Cerro del Carambolo aportan interesantes novedades. Una vez estudiado completamente el llamado "fondo se cabaña", pues Carriazo dejó una parte sin tocar como medida de seguridad, los directores de la campaña han llegado a la conclusión de que se trata de una fosa de forma irregular destinada al vertido de residuos producidos por el asentamiento. Ésta se encuentra dentro de una zona al aire libre que forma parte de un gran edificio exhumado durante esta actuación arqueológica. Por otro lado, el vertedero corta una estructura de adobes perteneciente a una etapa anterior de la construcción. Por lo tanto, la apertura del foso no puede ser de ningún modo más antigua que las primeras fases del yacimiento, cuya cronología está aún pendiente de ser concretada con exactitud dentro de la época colonial ${ }^{2}$. Esto significa que las cronologías elaboradas a partir de los materiales del estrato IV de Carriazo (fondo de cabaña) y que aportaban dataciones altas y anteriores a la llegada de colonos orientales, quedan descartadas, ya que el yacimiento del Carambolo parece ser de época colonial desde su fundación.

\section{SOBRE LA DECORACIÓN PINTADA TIPO CARAMBOLO}

La característica decoración de la CTC es más que conocida y también sobre ella se ha hablado mucho, sobre todo con el objeto buscar similitudes con otros estilos decorativos y discernir motivos peculiares que arrojen un poco de luz sobre su origen. Dentro de los tipos cerámicos considerados tradicionalmente tartésicos, la CTC comparte, como ya hemos referido, gran parte de sus peculiaridades con la cerámica grabada, coincidiendo en muchos elementos y temas decorativos, así como en formas y tratamientos.

Es evidente que los motivos principales que componen la decoración pintada en rojo de la CTC están dentro de un movimiento generalizado en todo el Mediterráneo, tanto central como oriental, que se caracteriza por el geometrismo. Como ya han señalado muchos autores desde Carriazo hasta hoy, la decoración se articula en bandas y líneas horizontales, entre las cuales, y por medio de otros trazos verticales, se van compartimentando espacios a diferentes niveles dentro de los cuales se suceden los motivos decorativos, como rombos, triángulos, cuadrados, mayas y ajedrezados. Éstos no suelen cubrir nunca la totalidad de la superficie del vaso, sino que se distribuyen sobre la mitad superior. Lo más común es que estén rellenos de un rayado de líneas más finas, siempre todo en rigurosa monocromía. Estas formas decorativas más

2. Todos loś nuevos datos que aquí citamos sobre El Carambolo proceden de una comunicación expuesta por los directores de la excavación, Álvaro Fernández Flores y Araceli Rodríguez Azogue (e.p.) en el III Simposio Internacional de Arqueología de Mérida. Congreso de Protohistoria del Mediterráneo Occidental. El Período Orientalizante, cuyas actas están actualmente en prensa. 
sencillas las podemos encontrar de manera general en las cazuelas carenadas y cuencos más pequeños. Dichos elementos geométricos algunas veces se complican aún más y forman aspas, rombos y hélices, todo distribuido en metopas que rodean el vaso. Estas formas más complejas están atestiguadas en un menor número que las más simples, y los encontramos, más comúnmente, sobre grandes vasos globulares.

Otro conjunto de elementos decorativos son los figurativos, los cuales M. S. Buero trató específicamente en un estudio (Buero 1984). Los motivos figurativos o naturalistas son los menos abundantes. Esta autora hace una doble clasificación y los divide en a) zoomorfos, fitomorfos y esteliformes, según su motivo, y en b) bandas, bandas con metopas, metopas o radiales, según su distribución (Buero 1984:350-351). Como podemos ver en la figura 3, los zoomorfos son los más numerosos, siendo el tema más repetido el de las aves. Las aves representadas se han identificado como ánades por sus numerosos paralelos, tanto en la Península Ibérica como fuera de ésta (Buero 1984: 361 ss.). La otra variedad de zoomorfos lo suelen componer animales astados. A los recogidos por M. S. Buero habría que añadir un fragmento obtenido en superficie en Mesas de Asta (Jerez de la Frontera) (González Rodríguez y otros 1995:229), publicado con posterioridad al estudio de Buero. Éste refleja un tipo de animal diferente. Los estudiados por la autora representan cápridos y en este nuevo fragmento observamos una especie de cérvido muy similar, como veremos, a los que encontramos en unos huevos de avestruz hallados en la necrópolis de Villaricos. Estos motivos suelen estar contenidos adornando tanto grandes vasos como cazuelas y cuencos.

La interpretación que Buero hace de estas representaciones y la relación que guardan con todo un mundo simbólico y religioso, como veremos más adelante, podría ser decisiva para llegar a otra posible interpretación de la funcionalidad de la CTC.

\section{FUNCIONALIDAD Y SIMBOLOGÍA}

Para determinar la utilidad, al menos de manera aproximada, de un tipo cerámico es necesario analizar ciertos factores como el entorno, en el que pueden aparecer evidencias de su uso. En ocasiones, la finalidad se puede relacionar también con la simbología de los motivos decorativos. En el caso de la CTC no es muy fácil determinar para qué sirvieron estos vasos. Hasta el momento, la idea más generalizada es que se trata de una vajilla de lujo usada por los habitantes de la cabaña-foso del Carambolo (en donde los grandes vasos servirían como sistema de almacenamiento). Esta afirmación se corrobora por sí misma, ya que el esfuerzo y el cuidado puesto en el acabado de estas piezas cerámicas hace pensar en un elevado coste de producción. El bruñido y la pintura suponen un trabajo que no merece la pena emplear en una vajilla de cocina. También por su escaso número y rareza se puede deducir que se trataba de un tipo especial. Por otro lado no es probable que se tratase de cerámica de cocina, ya que no se han encontrado huellas de que las cazuelas fuesen sometidas al fuego de los hogares (Buero 1987:46).

Respecto a la información que nos puede proporcionar la decoración, tampoco es mucha si nos fijamos en el conjunto general de motivos geométricos, cuya interpretación es muy dificultosa, dada la simplicidad y generalización de éstos. Como han expresado algunos autores, el uso decorativo de sucesiones de triángulos tramados, o dientes de lobo, se puede rastrear en la prehistoria andaluza desde el Calcolítico e incluso desde el Neolítico medio (Pellicer 1987-88:472), y posteriormente se encuentra de forma común por el Mediterráneo occidental durante la fase protogeométrica (Ruiz Mata 1984-85:240). Es muy difícil, por tanto, discernir qué significado simbólico, si tienen alguno, contenían dichas representaciones geométricas. Pero no sucede lo mismo con los motivos naturalistas presentes, aunque de manera más escasa, en la CTC y que, como se adelantó en el apartado anterior, pueden incluirse dentro de un lenguaje simbólico. Los animales representados en los vasos, especialmente las ánades, son atributos propios de una divinidad femenina de origen 
próximo oriental. Esta diosa aparece recogida con varios nombres en diferentes lugares de Oriente (Buero 1984:363). Se trata de una diosa con numerosas advocaciones, que generalmente tiene carácter materno, es señora del cielo, de la tierra y del mar, así como de la vida y la muerte, representa, por tanto, el ciclo vital. Suelen aparecer asociados a ella animales y símbolos que aluden a estas características. Esta misma simbología se recoge en los huevos de avestruz hallados en las necrópolis de Villaricos y La Laurita (fig.4).

En cuanto a la cronología, la costumbre de decorar huevos de avestruz con figuras de animales es muy antigua (Astruc 1951: 94) y se extiende como algo general por todo el Mediterráneo. En los huevos de las necrópolis citadas se recogen ciervos, aves, rosetas y estrellas, en ocasiones con diseños extraordinariamente parecidos a los de los vasos de la CTC. El uso de estos huevos tiene un matiz funerario muy concreto, ya que se creía que en ellos se contenía el hálito vital capaz de devolver la vida a los muertos (San Nicolás 1975: 75). He aquí el porqué estos huevos se decoraban con atributos de esta diosa, que a partir de ahora la nombraremos por uno solo de sus muchos nombres: Astarté. Ella representa el ciclo vital, tiene poder sobre la vida y la muerte, de ahí su carácter funerario y su presencia, a través de los huevos decorados, en las necrópolis de rito oriental fenicio. Los huevos de avestruz se han encontrado conteniendo restos de ocre, al igual que en algunos vasos de CTC (Buero 1987: 46) y depositados en otro tipo de ambientes religiosos como santuarios o templos y ofrendas fundacionales (Astruc 1951: 110). El significado simbólico y religioso del color ocre es algo registrado desde muy antiguo (desde el Paleolítico medio), y aceptado de manera general por la comunidad científica. Ante esta lectura simbólica de la decoración de la CTC, Buero se pregunta si estas piezas cerámicas formarían parte de algún culto oriental y si tendrían utilidad dentro de algún ritual que desconocemos (Buero 1984:362), pero se contesta a sí misma que esa interpretación está sin demostrar ya que, hasta ahora, la CTC habría aparecido en simples fondos de cabaña, los cuales no evidenciarían ningún tipo de uso ritual (Buero 1987:47).

Como es lógico, el análisis del entorno arqueológico y la funcionalidad del lugar en el que aparecen las piezas es también fundamental para su posterior interpretación. Así pues, deben tratarse las diferentes hipótesis que sobre el llamado "fondo de cabaña" del Carambolo Alto se han lanzado hasta ahora.

En la interpretación que hizo Carriazo señalaba que se trata de un fondo de cabaña, una estructura oval excavada en el suelo y que tendría una cubierta vegetal. La misma interpretación que posteriormente se ha hecho de fondos cabañas asociados a comunidades tartésicas, aunque no son muy abundantes. Esta interpretación es la que sostiene la mayoría de los investigadores. También se han hecho otro tipo de interpretaciones sobre el fondo de cabaña. Blanco en 1979 lo interpretó como lugar de culto típico del Egeo durante la etapa geométrica y orientalizante, lugares de estructura humilde, pero de rico ajuar. Posteriormente, en 1995, Blázquez (1983: 38) sugirió que la cabaña sería un santuario donde recibiría culto la diosa Astarté. Posteriormente el fondo de cabaña fue interpretado por Belén y Escacena (1998) como una fosa ritual, donde se arrojaban los restos de las ofrendas y de los sacrificios que se realizaban a la diosa Astarté en el templo, que sería lo que se había interpretado como el poblado bajo. Finalmente, los datos proporcionados por las actuales trabajos de campoen El Carambolo aportan luz al asunto, ya que como habíamos comentado anteriormente los excavadores han desechado la posibilidad de que la estructura "oval" que excavó Carriazo se trate de un fondo de cabaña, sino más bien de un foso de vertidos. Por otro lado, el resto de las estructuras aparecidas en esta campaña, especialmente un gran edificio denominado por los arqueólogos «Complejo A», así como otros elementos constructivos muy peculiares, señalan que nos encontramos ante un lugar de importancia y de carácter monumental. Este «Complejo A» y sus estructuras anejas destacan sobre el resto de los edificios exhumados en otras zonas del yacimiento y sobre los del Carambolo Bajo, tanto en el tamaño como en la calidad de los materiales usados para su construcción.

Si aceptamos la interpretación como fondo de cabaña, a pesar de lo descubierto recientemente, no tendríamos ningún dato extra, ninguna pista acerca de para qué se podía usar esta cerámica, interpretada, por tanto, simplemente como de lujo. También tendríamos que explicar de manera convincente a qué se debe 
el que en un espacio tan reducido como es el área oval del fondo de cabaña se haya recogido tanta cantidad de cerámica y por qué tan fragmentada. Carriazo ya se percató de este problema. Si aceptamos, por el contrario, cualquiera de las hipótesis que hace del yacimiento un lugar de culto a Astarté, y del foso el destino final de los elementos usados en los ritos celebrados en él, encontramos un hueco perfecto en este complicado puzzle para colocar la pieza de la CTC. ¿Sería lógico pensar en una utilidad ritual de esos vasos, en un entorno sacro dedicado a Astarté?, ya que, como se menciona más arriba, estos recipientes poseen ciertos elementos decorativos concomitantes con la simbología propia de la diosa. La cerámica, interpretada como de uso ritual, y el santuario de Astarté se justificarían mutuamente. Otros elementos usados como argumento por Belén y Escacena refuerzan esta idea, una vez realizada una minuciosa revisión del material hallado por Carriazo. Éstos poseen también atributos de la diosa, como el ave de terracota y la roseta en el fondo del plato, entre otros (Belén y Escacena 1998).

\section{CONCLUSIÓN}

\section{$[\ldots]$}

$\mathrm{Al}$ andar se hace camino, y al volver la vista atrás se ve la senda que nunca se ha de volver a pisar. [...]

Antonio Machado. Campos de Castilla.

Estos versos de Machado podrían ser un magnífico resumen de la idea expuesta en este trabajo, si se identifica "el camino" con los enfoques metodológicos y las diferentes hipótesis que sobre Tartessos se han ido planteando a lo largo de todos estos años. El camino de la investigación arqueológica sobre Tartessos ha sido breve, y se ha ido pavimentando poco a poco con datos que han ido surgiendo a la vez que se avanzaba por esta senda. Estos nuevos enfoques sugieren tener una visión de Tartessos diferente a la que en su momento tuvieron Schulten o Carriazo. Y realmente así ha sido: la opinión ha ido cambiando. Con el tiempo han caído pesados axiomas que sobre la cultura tartésica se habían acuñado en aquellos primeros años de investigación. Quizá la CTC sea uno de esos axiomas inamovibles que debamos revisar a la luz de los recientes hallazgos e hipótesis de trabajo. Los dos primeros apartados del presente artículo intentan reflejar algunos factores que propiciaron que El Carambolo fuese interpretado como un poblado tartésico y la cerámica que había en el fondo de aquella supuesta cabaña como el registro material de la, hasta entonces, invisible cultura de Tartessos. Si recuerdan las palabras de Carriazo citadas al principio de nuestro trabajo acerca del carácter tartésico del tesoro del Carambolo, él mismo admite que en su dictamen inicial sobre la pertenencia a lá cultura tartésica de la CTC existía "alta dosis de intuición". A los factores ya citados puede añadirse, por ejemplo, el hecho de que en aquel momento el estado de la investigación hacía imposible contemplar la posibilidad de asentamientos fenicios tan alejados de la costa. Por el contrario, el conocimiento actual de la paleogeografía del Guadalquivir demuestra que El Carambolo no fue en ningún momento un asentamiento del interior, sino muy cercano a la paleodesembocadura del río (fig. 1). También hay que mencionar que el conocimiento de los asentamientos fenicios de la Costa del Sol y la investigación arqueológica de Tartessos nacieron y crecieron a la vez. Así pues, los trabajos de tipificación de los bagajes cerámicos de ambas culturas se desarrollaron a un mismo tiempo, en un momento en que se sabía bastante poco de los yacimientos fenicios de Oriente. Es decir, desde el principio y de manera simultánea se adjudicaron las tradiciones alfareras a tartesios y fenicios usando criterios como la utilización o no del torno industrial. Hoy sabemos que los fenicios también usaban cerámica a mano, con lo que esto deja de ser un criterio aceptable. 
Quizá el estado actual de la investigación y las nuevas aportaciones del Carambolo, junto con otras teorías que ahora se barajan para la interpretación del yacimiento, permitan ver la CTC como parte de la vajilla ritual usada por orientales para dar culto a la diosa Astarté en su santuario sobre el cerro. Se ha propuesto el carácter foráneo de la gente que hacía uso de un santuario urbano situado en el solar de la casa-palacio del Marqués de Saltillo (Carmona) a través de la lectura simbólica de sus ajuares (Belén y otros 1997). ¿Podría realizarse una lectura similar con la CTC? La similitud existente entre algunos motivos decorativos usados por las comunidades orientales en los huevos de avestruz y los que encontramos en la CTC, ¿podría interpretarse como un mismo lenguaje simbólico usado por una misma gente (fenicios occidentales) para plasmar sus mismas creencias religiosas? Es evidente que una respuesta afirmativa a esta cuestión anularía la interpretación tradicional según la cual la CTC sería el producto de las influencias geométricas mediterráneas sobre la tradición ceramista local. En cincuenta años de investigaciones, elementos culturales y asentamientos que se tenían por autóctonos han pasado a ser de las comunidades foráneas fenicias, y ello no tanto por la acumulación de nuevos datos como por el cambio en las hipótesis de trabajo de los investigadores. Doña Blanca es un caso paradigmático de estas transformaciones (Ruiz Mata 1986 y 1999). Los análisis de pastas realizados por V. Galván a la CTC de Huelva revelan que su procedencia del ámbito sevillano por contener tremolita, un elemento ausente en las arcillas onubenses (Ruiz Mata y Fernández Jurado 1986: 297). ¿Podría, por este dato, tomarse este tipo cerámico, aceptando su carácter simbólico y religioso, como algo exclusivo del Carambolo, desde donde era distribuido a otros lugares del suroeste andaluz?

Las reflexiones contenidas en el título del presente trabajo deben concluir con la idea de una necesario replanteamiento de la interpretación de la CTC. Es conveniente el abandono de axiomas arqueológicos acuñados al comienzo de las investigaciones y, como indican los versos de Machado, al volver la vista atrás ver un camino que tal vez no se deba volver a pisar.

\section{BIBLIOGRAFÍA}

ALMAGRO-GORBEA, M. (1977): El Bronce Final y el Período Orientalizante en Extremadura (Bibliotheca Praehistorica Hispana XIV). Madrid, Consejo Superior de Investigaciones Científicas.

AMORES, F. (1995): "La cerámica pintada estilo Carambolo: una revisión necesaria de su cronología", Tartessos, 25 años después 1968-1993 (Jerez de la Frontera): 159-178. Jerez de la Frontera, Ayuntamiento de Jerez de la Frontera.

ASTRUC, M. (1951): La necrópolis de Villaricos (Informes y Memorias 25). Madrid, Ministerio de Educación Nacional.

AUBET, M. E. (1982): "Un vaso a mano con decoración pintada de los Alcores de Carmona”, Trabajos de Prehistoria 39: 385-388.

AUBET, M. E. (1992): Maluquery la renovación de la arqueología tartésica (Clásicos de la Arqueología de Huelva 5). Diputación Provincial de Huelva, Huelva.

BELÉN, M.; ANGLADA, R.; ESCACENA, J. L.; JIMÉNEZ, A.; LINEROS, R. y RODRÍGUEZ, I. (1997): Arqueología en Carmona (Sevilla). Excavaciones en la Casa-Palacio del Marqués de Saltillo. Sevilla, Consejería de Cultura de la Junta de Andalucía.

BELÉN, M. y ESCACENA, J. L. (1998): "Testimonios religiosos de la presencia fenicia en Andalucía occidental", en ElMediterráneo en la Antigüedad: Oriente y Occidente (Cunchillos y otros eds.) Sapanu. Publicaciones en Internet II, http://www.labherm.csic.es.

BENDALA, M. (1991): “El arte Tartésico”, Cuadernos de Arte Español 1. Madrid, Historia 16. 
BLANCO, A. (1979): Historia de Sevilla I. (1) La Ciudad Antigua (Desde la prehistoria a los visigodos). Sevilla, Universidad de Sevilla.

BLÁZQUEZ, J.M. (1983): Religiones Prerromanas. Primitivas religiones ibéricas, tomo II. Madrid, Cristiandad.

BONSOR, G. (1997 [1899]): Las colonias agrícolas prerromanas del valle del Guadalquivir. Écija, Gráficas Sol.

BUERO, M. S. (1984): "Los motivos naturalistas en la cerámica pintada del Bronce Final del Suroeste peninsular", Habis 15: 345-364.

(1987): "El Bronce Final y las cerámicas tipo Carambolo", Revista de Arqueología 70: 35-47.

CABRERA, P. (1981): "La cerámica pintada de Huelva", Huelva Arqueológica V: 317-335.

CARO BELLIDO, A.; ACOSTA, P. y ESCACENA, J. L. (1986): "Informe sobre la prospección arqueológica con sondeo estratigráfico en el solar de la calle Alcazaba (Lebrija-Sevilla)", Anuario Arqueológico de Andalucía / 1986. II, Actividades Sistemáticas: 168-174. Sevilla, Junta de Andalucía.

CARRIAZO, J. (1969) "El Cerro del Carambolo", Tartessos y sus problemas. V Symposium Internacional de Prehistoria Peninsular: 311-340. Barcelona, Universidad de Barcelona.

- (1973): Tartesos y el Carambolo. Madrid, Patronato Nacional de Museos.

CASTRO, P. V.; LULL, V. y MICÓ, R. (1996): Cronología de la Prehistoria Reciente de la Península Ibérica y Baleares (c. 2.800-900 cal ANE). Oxford, BAR Internacional series 652.

ESCACENA, J. L. (1995): “Etapa precolonial de Tartessos. Reflexiones sobre el «Bronce» que nunca existió", Tartessos, 25 años después 1968-1993(Jerez de la Frontera): 179-214. Jerez de la Frontera, Ayuntamiento de Jerez de la Frontera.

FERNÁNDEZ FLORES, A. y RODRÍGUEZ AZOGUE, A. (e.p.): "Nuevas excavaciones en el Cerro del Carambolo. Resultados preliminares", III Simposio Internacional de Arqueología de Mérida. Congreso de Protohistoria del Mediterráneo Occidental. El Período Orientalizante. (Mérida, 2003).

FERNÁNDEZ JURADO, J. (1989-90): "La Huelva Tartésica", Annali della Facoltá di lettere e Filosofia. 1 Studi Classici XXVII, nuova serie XIII: 243-269.

GONZÁLEZ RODRÍGUEZ, R.; BARRIONUEVO, F. y AGUILAR, L. (1995): "Mesas de Asta, un centro indígena tartésico en los esteros del Guadalquivir", Tartessos, 25 años después 1968-1993 (Jerez de la Frontera): 215-237. Jerez de la Frontera, Ayuntamiento de Jerez de la Frontera.

MALUQUER, J. (1984): Tartessos. Barcelona, Destino.

PELLICER, M. (1962): Excavaciones en la Necrópolis púnica de "Laurita" del cerro de San Cristóbal (Almuñecar, Granada). Excavaciones Arqueológicas en España XVII. Madrid, Ministerio de Educación Nacional.

- (1969): "Las primeras cerámicas a torno pintadas andaluzas y sus problemas", Tartessos y sus problemas. V Symposium Internacional de Prehistoria Peninsular: 291-310. Barcelona, Universidad de Barcelona.

_- (1987-88): "La cerámica a mano del Bronce Reciente y del Orientalizante en Andalucía occidental" Habis 18-19: 461-485.

RUIZ MATA, D. (1980): "El Bronce Final -fase inicial-en Andalucía Occidental. Ensayo de definición de unas cerámicas", Archivo Español de Arqueología LII: 3-15.

(1984-85): "Puntualizaciones sobre la cerámica pintada tartésica del Bronce Final-Estilo Carambolo o Guadalquivir I-", Cuadernos de Prehistoria y Arqueología de la UAM 11-12 (I): 245-253.

(1986): “Aportación al análisis de los indicios de la presencia fenicia en Andalucía sudoccidental, según las excavaciones del Cabezo de San Pedro (Huelva), San Bartolomé (Almonte, Huelva), Castillo de Doña Blanca (Puerto de Santa María, Cádiz) y El Carambolo (Camas, Sevilla)", en Homenaje a Luis Siret (1934-1984): 537-556. Sevilla, Consejería de Cultura. 
(1995): "Las cerámicas del Bronce Final. Un soporte tipológico para delimitar el tiempo y el espacio tartésico", Tartessos, 25 años después 1968-1993(Jerez de la Frontera): 265-313. Jerez de la Frontera, Ayuntamiento de Jerez de la Frontera.

_- (1999): "La fundación de Gadir y el Castillo de Doña Blanca: contrastación textual y arqueológica", Complutum 10: 279-317.

RUIZ MATA, D. y FERNÁNDEZ JURADO, J. (1986): El yacimiento metalúrgico de época tartésica de San Bartolomé de Almonte (Huelva). Huelva Arqueológica VIII. Huelva, Diputación de Huelva.

SAN NICOLÁS, M. P. (1975): "Las cáscaras de huevo de avestruz fenicio-púnicas en la Península Ibérica y Baleares", Cuadernos de Prehistoria y Arqueología de la UAM 2: 75-100.

SCHATTNER, T. G. (2000): "Formas de Grecia Oriental en la cerámica "tartésica"”, Habis 31: 63-72. SCHULTEN, A. (1945 [1922]): Tartessos. Madrid, Espasa -Calpe. 

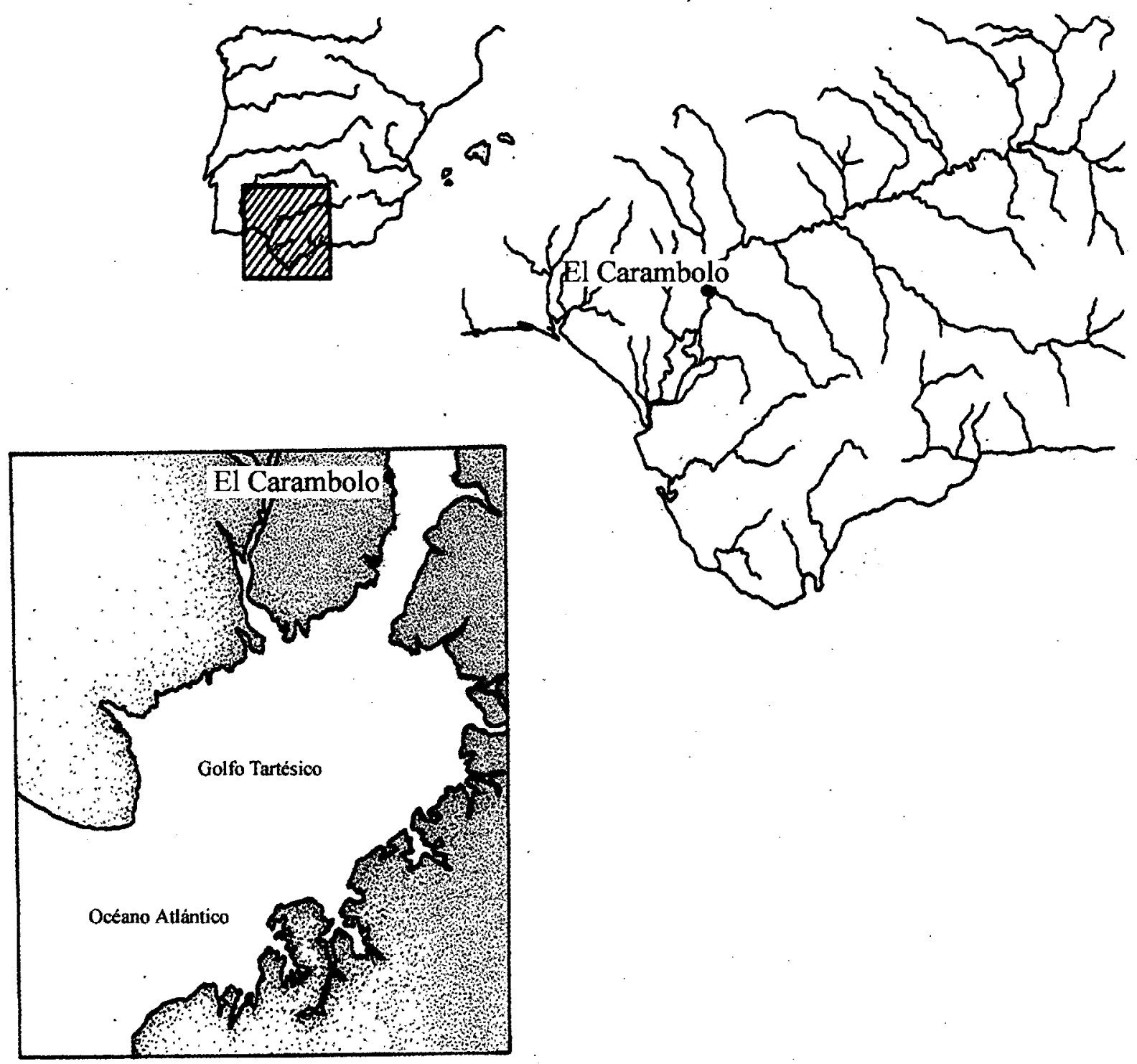

Fig.1.Situación de El Carambolo en la península y en la paleodesembocadura del Guadalquivir. 

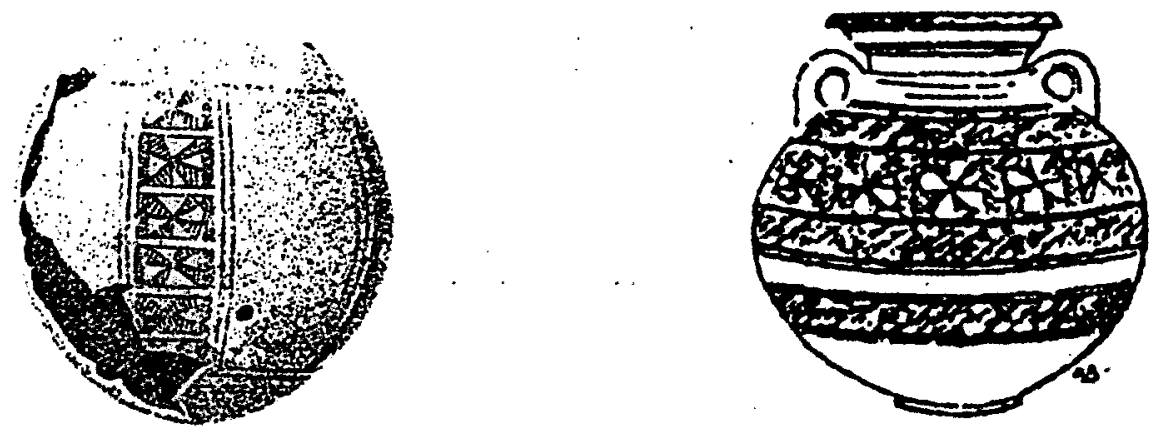

))
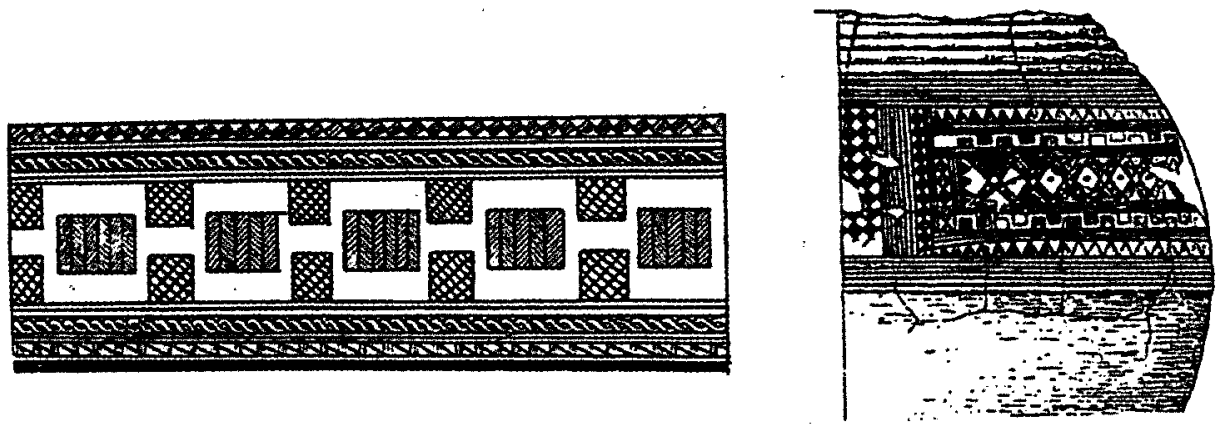

b)

Fig. 2. Similitud entre los motivos geométricos de cáscaras de huevos de avestruz y motivos de la CTC a) según Pellicer (1962) y Bonsor (1997 [1899]) b) según Carriazo (1973). 

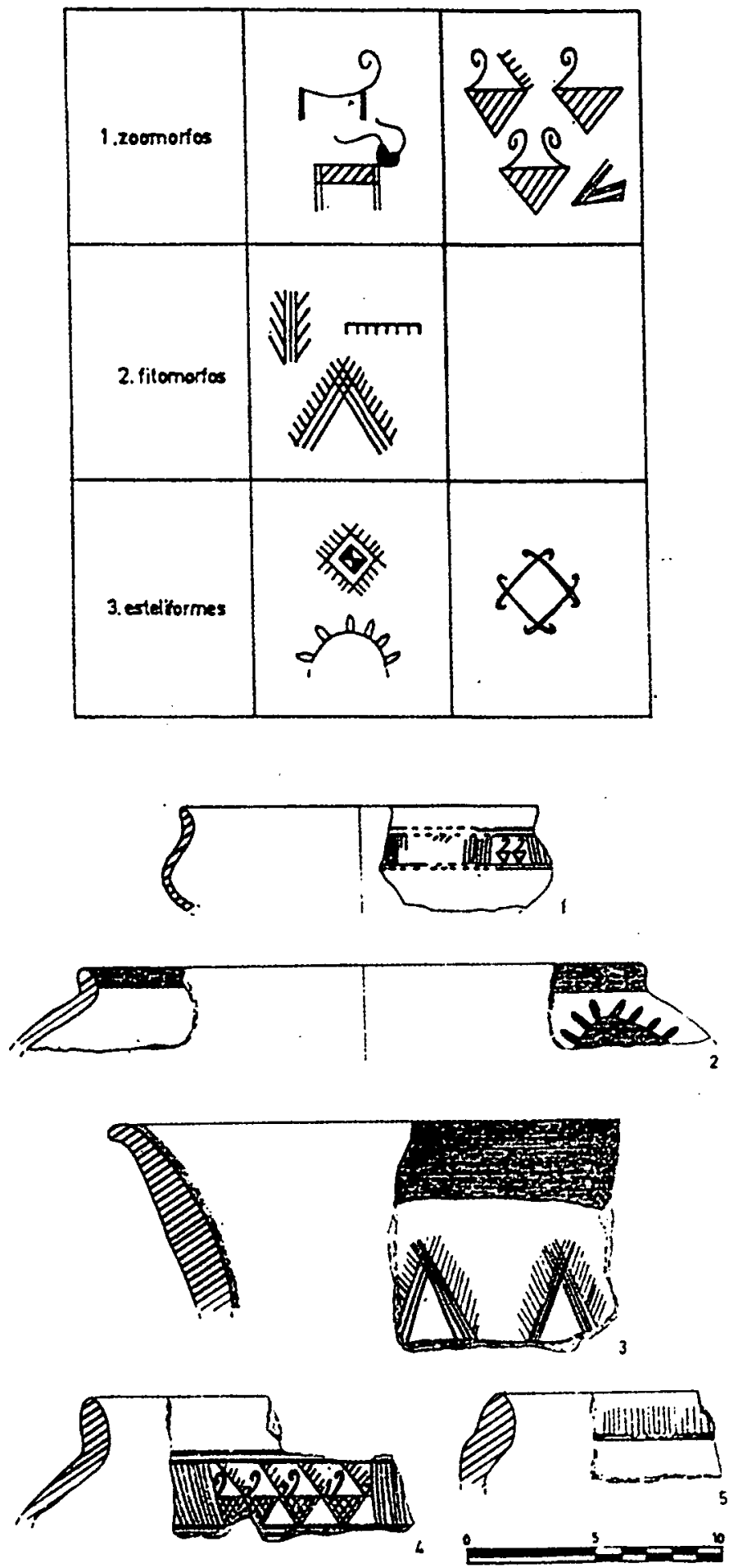

Fig. 3. Motivos naturalistas en la CTC (Buero 1984) 


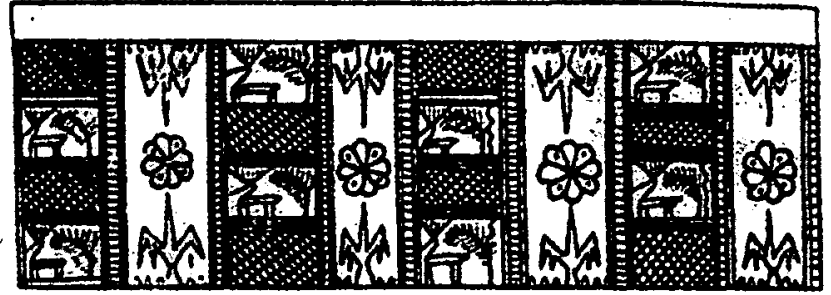

I

Cérvidos

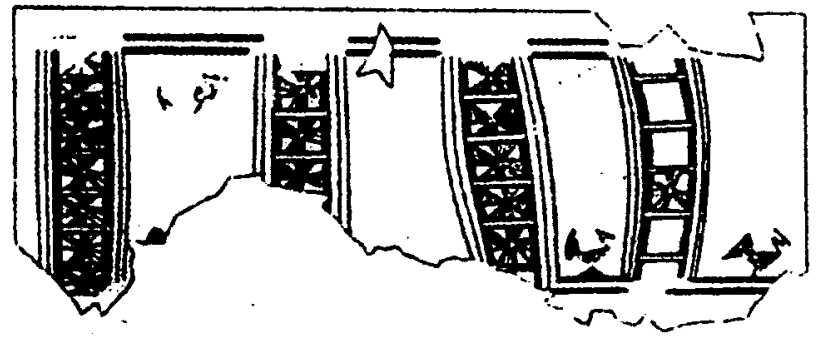

2

Anades
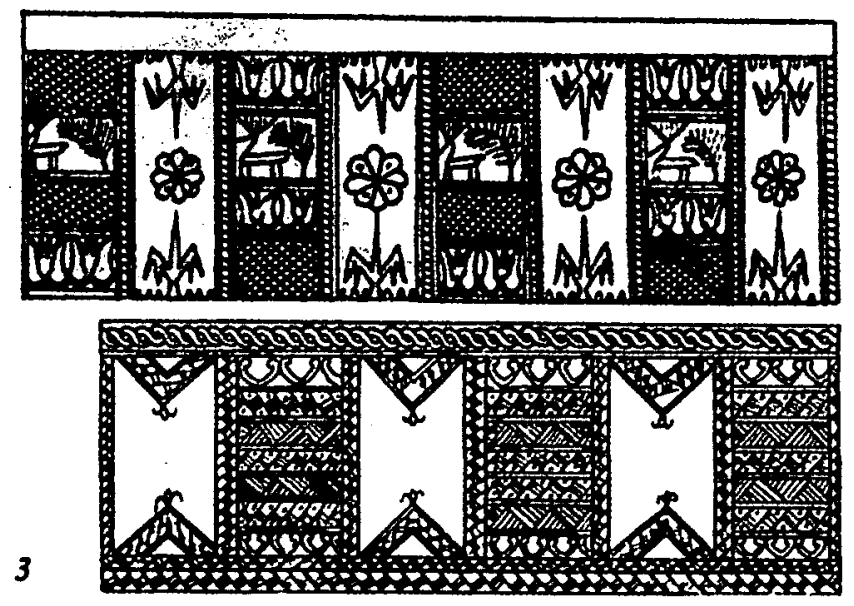

Fitomorfos y Esteliformes

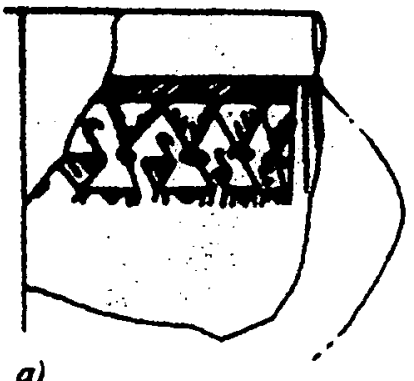

a)

b)
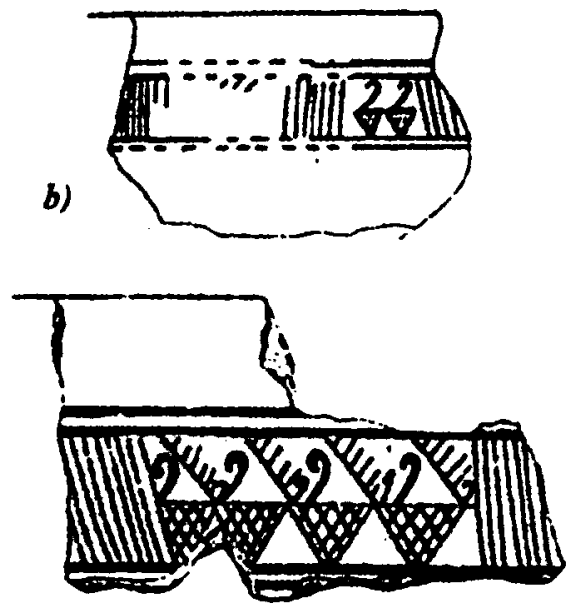

c)

d)

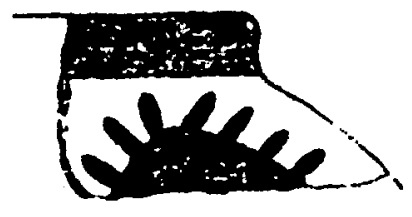

e)

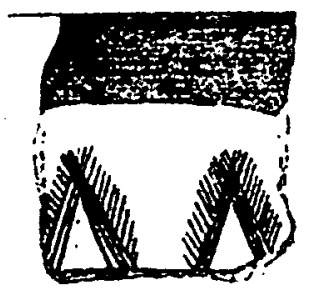

Fig. 4. Similitud de motivos naturalistas entre cáscaras de huevos de avestruz (Astrue 1951; Pellicer 1962) y la CTC (Buero 1984; González Rodríguez y otros 1995). 